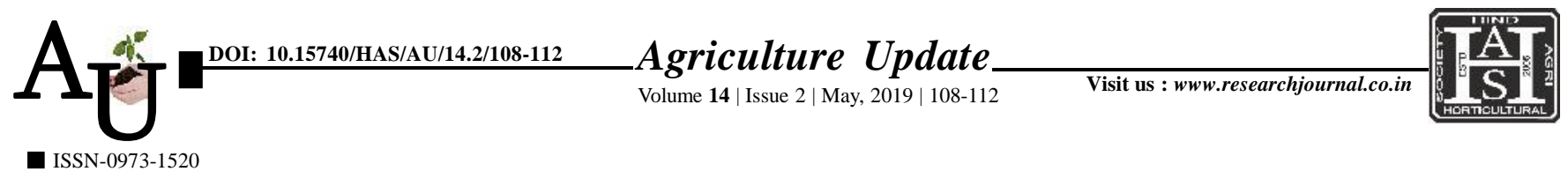

\title{
Research article: Constraints faced by farmers in utilization of information and communication technologies (ICTs)
}

\section{A. Parvathy and S. S. Dolli}

Article Chronicle : Received :

18.02.2019;

Revised :

03.04.2019;

Accepted :

04.05.2019

KEY WoRds:

Constraint index, Infrastructural constraints, Technical constraints, Utility constraints

Author for correspondence:

\author{
A. Parvathy \\ Department of \\ Agricultural Extension \\ Education, College of \\ Agriculture, University of \\ Agricultural Sciences, \\ Dharwad (Karnataka) \\ India \\ Email:paroos07@gmail. \\ com
}

See end of the article for

authors' affiliations
SUMMARY : Information and communication technologies can have a significant impact in area of agricultural extension, which depends to a large extent on exchange of information between and among farmers and a broad range of other actors viz., researchers, extension workers, input dealers, market functionaries etc. Considering the importance of ICT in transfer of technology among agricultural stakeholders, it was felt necessary to find out the major constraints which hinder the utilization of ICTs by farmers. Therefore, present investigation was undertaken with the objective to study the constraints faced by farmers in utilization of information and communication technologies. The study was conducted in selected districts of Karnataka and Kerala states in India during the year 2016-18. Ninety farmers were selected randomly from Dharwad district in Karnataka and Thrissur district in Kerala (45 each) to study the constraints in utilization of information and communication technologies (ICTs) by farmers. The data were collected from each farmer, through personal interview method with the help of structured schedule. Regarding farmers of Karnataka, lack of infrastructure facilities was ranked first among infrastructure constraints with an index of 38.89 per cent followed by low network coverage (CI=31.11 $\%)$. Among affordability constraints, high cost of ICT gadgets was ranked first for farmers of Karnataka $(\mathrm{CI}=50.00 \%)$ and Kerala $(\mathrm{CI}=55.56 \%)$. Lack of confidence in using ICT $(\mathrm{CI}=27.78 \%)$ and lack of time to utilize ICT tools $(\mathrm{CI}=32.22 \%)$ were the major socio-psychological constraints faced by farmers in Karnataka and Kerala, respectively. Lack of training on ICT tools was the major technical constraint faced in using ICTs by farmers of Karnataka (75.56 \%) and Kerala (72.22 \%). Major utility constraint faced was lack of locally relevant information as expressed by almost sixty five per cent of farmers from Karnataka $(\mathrm{CI}=65.56 \%)$ and Kerala $(\mathrm{CI}=66.67 \%)$.

How to cite this article : Parvathy, A. and Dolli, S.S. (2019). Constraints faced by farmers in utilization of information and communication technologies (ICTs). Agric. Update, 14(2): 108-112; DOI : 10.15740/HAS/AU/ 14.2/108-112. Copyright@ 2019: Hind Agri-Horticultural Society. 